\title{
A Study of Risk Factors of Stroke in Patients Admitted in Manipal Teaching Hospital, Pokhara.
}

\author{
Maskey A, Parajuli M, Kohli S C
}

Department of Medicine

Manipal Teaching Hospital

Pokhara, Nepal

Corresponding Author

Abhishek Maskey

Department of Medicine

Manipal Teaching Hospital

Pokhara, Nepal.

Email: maskey21@hotmail.com

Citation

Maskey A, Parajuli M, Kohli S C. A Study of Risk Factors of Stroke in Patients Admitted in Manipal Teaching Hospital, Pokhara. Kathmandu Univ Med J 2011;36(4):244-7.

\begin{abstract}
Background

Stroke is usually end result of predisposing conditions that originated years before the ictus. Identification of its modifiable risk factors can help in planning preventive strategies.
\end{abstract}

\section{Objective}

To study the risk factors of stroke in adult patients.

\section{Methods}

A hospital based prospective cross sectional study was carried out in 160 stroke patients admitted in Manipal Teaching Hospital, Pokhara from November 2007October 2010. Diagnosis of stroke was confirmed by CT scan of brain. Patients were then investigated for presence of conventional risk factors. The data was statistically analysed using Epi-Info.

\section{Results}

The mean age of stroke patients was 65.98 years \pm 10.69 with $126(78.8 \%)$ of patients belonging to age group $\geq 60$ years. It afflicted higher percentage of males 104 $(65 \%)$ than females 56 (35\%). Analysis of stroke subtypes showed preponderance of haemorrhagic stroke in 85 (53.1\%) as against infarction in 75 (46.9\%) of cases. Other conventional modifiable risk factors were seen as follows: hypertension 98 (61.2\%), cigarette smoking 95 (59.4\%), alcohol use 43 (26.9\%), left ventricular hypertrophy $44(27.5 \%)$, atrial fibrillation $37(23 \%)$, elevated triglyceride $37(23 \%)$, diabetes mellitus $15(9.3 \%)$ and elevated total cholesterol 12 (7.5\%). Multiple risk factors ( $\geq 2)$ were seen in $122(76.5 \%)$ cases.

\section{Conclusions}

The maximum occurrence of stroke was seen in patients $>60$ years. Overall male preponderance and higher occurrence of haemorrhagic stroke was seen in our study. Significant risk factors in order of descending order were hypertension, cigarette smoking, left ventricular hypertrophy, alcohol use, atrial fibrillation and elevated triglycerides.

\section{KEY WORDS}

haemorrhagic stroke, ischaemic stroke, risk factors

\section{INTRODUCTION}

Several population based epidemiological studies have focused on identification of risk factors for stroke. The Framingham profile consisting of elevated systolic blood pressure, elevated serum cholesterol level, glucose intolerance, cigarette smoking and left ventricular hypertrophy identifies persons at highest risk of stroke. ${ }^{1}$

The risk factors for stroke vary internationally. Its risk factor profile may differ in different population groups. Details assessment of its underlying risk factors in stroke population of a country is relevant to understanding aetiology and planning preventive strategies to reduce future stroke burden. There are limited studies available on the subject in Nepal. Three important clinical studies on the subject were published in the year 2006. The first one year prospective study on clinicoradiological profile of stroke in eastern Nepal done at B P Koirala Institute of Health Sciences, Dharan. ${ }^{2}$ A five year retrospective review by Devkota et al and a two year retrospective study by Pathak et al from Nepal Medical College Teaching Hospital were published in the same year., 
This hospital based prospective study of 160 cases has been undertaken to study the risk factors of stroke subtypes in Western region and to compare our results with those of previous studies done in Nepal.

\section{METHODS}

This is hospital based prospective study conducted in tertiary care hospital of western region from November 2007 to October 2010. The study included 160 cases of stroke patients where diagnosis was confirmed by CT scan of brain.

Detail clinical history was obtained and clinical examination performed as per standard proforma. Blood haemogram, sugar, lipid profile, urea, creatinine, electrolytes and 12 lead ECG was performed in all the cases. Echocardiography was done in selected cases. Carotid Doppler studies was done where indicated. The patients were categorized as Infarction or haemorrhagic stroke based on CT findings. Risk factors were evaluated in all the cases. Hypertension was considered to be present if history or treatment of hypertension was present. History of smoking was translated into pack years. Forty three patients in the study consumed home made alcohol for ten years or more in excess of $500 \mathrm{ml}$ per day. History of diabetes mellitus or its treatment was obtained in all the cases. Further investigations were done as indicated. Upper limit of total blood cholesterol, low density lipoprotein and triglyceride were 220mg/ $\mathrm{dl}, 165 \mathrm{mg} / \mathrm{dl}$ and $170 \mathrm{mg} / \mathrm{dl}$ respectively as per our lab reference values. Clinical findings of atrial fibrillation were confirmed by Electrocardiogram. Left ventricular hypertrophy was confirmed by electrocardiogram and echocardiography in selected cases. For the purpose of analysis, the patients were divided into three age groups 20-39 years, 40-59 years and 60 years and above. Further subdivision into male and female patients was done for each group. The resultant data was compiled and entered in excel sheet and analyzed using epi-info.

\section{RESULTS}

There were total of 160 cases included in this study, of which 104 were males and 56 females. The mean age was 65.98 years (SD 10.69). Age and sex distribution of cases is given in table $\mathrm{I}$.

Table1. Age and sex distribution of cases.

\begin{tabular}{llll}
\hline AGE (years) & MALE & FEMALE & TOTAL \\
\hline $20-39$ & 2 & 1 & 3 \\
\hline $40-59$ & 17 & 14 & 31 \\
\hline$\geq 60$ & 85 & 41 & 126 \\
\hline
\end{tabular}

Out of 160 cases, 75 (46.9\%) had infarction while 85 (53.1\%) suffered hemorrhagic stroke. There was no significant difference in occurrence of infarction or hemorrhagic stroke in patients of the age group 60 years and above. Out of 126 cases in this group 64 suffered from infarction and 62 cases suffered from hemorrhagic stroke.

In contrast to above, out of total 31 cases in the age group 40-59 years, $23(74.2 \%)$ cases suffered from hemorrhage while only $8(25.8 \%)$ cases had infarction. $82.3 \%$ of male and $64.3 \%$ of female cases in this group suffered from hemorrhage.

Amongst the modifiable risk factors, hypertension was seen in $98(61.2 \%)$ cases and constituted largest single risk factor. Hypertension was present in 98 (78\%) of patient with 60 years and above age group and 23 (74\%) of patients 40-59 years. Cigarette smoking (10 pack years or more) was present in 95 (59.4\%) cases. Excessive alcohol use (half liter and above per day for more than 10 years) was present in 43 (26.9\%) cases. Atrial fibrillation was present in 37 (23\%) cases while evidence of left ventricular hypertrophy was seen in 44 (27.5\%) of cases. 25 (67.5\%) cases showing atrial fibrillation showed infarction and 12 (32.5\%) had haemorrhage. The corresponding figures for left ventricular hypertrophy for infarction and hemorrhage were 14 (31.9\%) and 30 (68.1\%) respectively.

Diabetes mellitus was present in 15 (9.3\%) of cases. Elevated triglyceride levels were seen in $37(23 \%)$ cases. Raised total cholesterol 12(7.5\%). Raised LDL in 5 (3\%) cases.

\section{DISCUSSION}

The mean age of stroke in our study was 65.98 years (SD 10.69 , range $34-91$ years). Lower mean age of stroke have been reported in three previous Nepali studies. Naik et al reported a figure of 58.27 years (range 7-91 years) in their study. ${ }^{2}$ This appears to be due to inclusion of younger patients in their study as compared to ours. The mean age reported by Pathak et al and Devkota et al were 61 years and $61.7 \pm 14.9$ years respectively. ${ }^{3,4}$ Our figure of 65.98 years compares well with mean age of 64.5 years reported in a study from Ceylon where an almost similar age range of patients (37-94 years) were included in the study. ${ }^{5}$

The maximum number of stroke patients $126(80 \%)$ were seen in age group 60 years and above. This compares well with US center for Disease control and prevention and heart disease and stroke statistics 2010 update American heart Association which states that nearly three quarters of stroke occur in people over age of 65years. ${ }^{6}$

The mean age of stroke in Western countries was reported to be between $76-80$ years. ${ }^{7}$ In general, the mean age of stroke in Asian subcontinent is reported to be lower than western studies and were as follows $66 \pm 13.6$ (Mumbai, India), 52 to 66 years (Pakistan), $60.0 \pm 13.7$ years ( bangladesh ) and 64.5 range 37-94 years (Srilanka). ${ }^{5,8-10}$ The younger mean age group in Asian subcontinent may reflect younger mean age of the population or the stroke risk may occur in younger age in Asian subcontinent than in the western countries. 
Our study showed that stroke affected higher number of males 104 (65\%) than females 56 (35\%). The corresponding figures of another study in eastern Nepal were $69.3 \%$ and $30.7 \%$ respectively. ${ }^{2}$ The findings of the above two studies follow the global trend of male preponderance of stroke.

Another important finding in our study was higher occurrence of haemorrhagic stroke was higher 85 (53.15\%) than infarction 75 (46.9\%) when all age groups were considered together. Incidence of infarction is much higher than haemorrhagic stroke in general population. ${ }^{11}$ The reason for higher number of haemorrhagic stroke seen in our study may be due to exclusion of patient, younger than 20 years.

Out of modifiable risk factors, hypertension was present in $98(61.2 \%)$ of cases and emerged as largest risk factor in our study. It was seen in $60 \%$ of cases in the series reported by Pathak et al. ${ }^{4}$ However hypertension was present in much lower percentage of cases in other Nepali studies (47.2\% Devkota et al 3 and $40 \%$ by Naik et al. ${ }^{2}$ Lower rates of hypertension reported in above two series cannot be commented upon. However increasing trends towards the development of hypertension in Nepal may be a factor for its higher rates reported in recent series and merits further studies. Hypertension is a major stroke risk factor in industrialized countries and was most common in South Asian and Western studies. ${ }^{9}$

Smoking ranked next to hypertension and was present in 95 (59.4\%) cases in our study. It was reported in 61\% and $58.3 \%$ of cases by Pathak et al and Devkota et al respectively.,4 Smoking emerged as commonest risk factor in the study reported by Naik et al. ${ }^{2}$ It was present in $40.66 \%$ of cases in their series. This amply signifies importance of smoking as a major risk factor of stroke in context of Nepali population.

History of alcohol consumption in excess of $500 \mathrm{ml}$ for more than ten years was present in 43 (26.9\%) of cases of stroke in our series. Alcohol consumption as a risk factor has been reported in $30.66 \%$ by Naiket al and $18 \%$ by Pandit et al. ${ }^{2,12}$

Diabetes Mellitus was present in 15 (9.3\%) of cases in our series. Similar lower figures of $6.6 \%, 11 \%$ and $11.1 \%$ have been reported in other Nepali studies by Naik et al, Pandit et al and Devkota et al respectively. ${ }^{2,3,12}$ Diabetes mellitus as a risk factor of stroke appears to rank lower in Nepal as per findings of all studies.

Raised total cholesterol was found in 12 (7.5\%) of our cases while high triglycerides levels were seen in 37 (23\%) of cases. Their role as risk factor of stroke cannot be commented upon and further studies are needed in this field.

Atrial fibrillation was present in 37 (23\%) of cases out of which $26(71.4 \%)$ suffered from infarction in our series. It was reported in $12.5 \%$ by Devkota et al. ${ }^{3}$

Left ventricular hypertrophy was seen in 44 (27.5\%) of cases of stroke in our study. Atrial fibrillation has been found to be an independent risk factor of stroke, increasing risk about five fold as per recent data. ${ }^{6}$

Multiple risk factors (two or more) were present in 81 (76.5\%) cases in our study. Naik et al also reported similar high figure of $70.2 \%$ in their series. ${ }^{2}$ Alcohol and smoking was commonest combination in their series. However, hypertension and smoking (57\%) was commonest in our series.

\section{CONCLUSION}

The mean age of stroke in adult population was 65.98 \pm 10.69 years and was higher than those reported in other studies.The maximum number of cases of stroke occurred in age group 60 years and above. Infarction and haemorrhagic stroke occurred almost equally in this age group. In the younger age group (40-59 years), haemorrhagic stroke predominated. It was also seen that stroke afflicted higher number of males than females in all age group. When all age group were considered together, occurrence of haemorrhagic stroke was higher (53.15\%) than infarction (46.9\%)

Of the modifiable risk factors, hypertension was most common, followed by cigarette smoking and alcohol use. Diabetes mellitus and raised total cholesterol levels were seen only in small percentage of cases.

Preventive strategies aimed at early detection and treatment of hypertension, public awareness about ill effects of cigarette smoking and excessive alcohol use can contribute in reduction of stroke burden. Suitable measures to reduce the stroke risk can be adopted as primary and secondary prevention in these cases.

\section{REFERENCES}

1. Kannel WB, Wolf P A. Epidemology of cerebrovascular disease. Russel R W. editor. Vascular disease of Central Nervous System.Edinburgh; Churchill Livingstone. 1983;1-24.

2. Naik M, Rauniyar RK, Sharma UK, Dwivedi S, Karki DB, Samuel JR. Clinicoradiological profile of stroke in eastern Nepal, a computed tomography study. Kathmandu Univ Med J 2006;4(2):161-6.

3. Devkota KC, Thapamagar SB, Malla S. Retrospective analysis of stroke and its risk factors in Nepal Medical college Teaching hospital. Nepal Med Coll J 2006;8(4):269-75.

4. Pathak V, Kanth R, Pant. Stroke: A case series in Nepal Medical College Teaching Hospital. Nepal med coll J 2006;8(3):180-1.

5. Gunatilake SB, Jayasekera BA, Premawardane AP. Stroke subtypes in Srilanka- A hospital based study. Ceylon Med J 2001; 46 (1): 19-20.

6. Center for Disease Control and Prevention. Heart disease and stroke statistics (Internet). Updated 2010. [Available from : www.cdc.gov/ heartdisease/facts.htm]

7. Grimley E J. The Epidemiology of Stroke. Age and Ageing. Oxford journals 1979;8:50-56.

8. Dalal P M, Malik S, Bhattacharjee M, Trivedia N D, Vairale J, Bhata P, Deshmukh S, Khandelwal K, Mathur V D. Population-Based Stroke Survey in Mumbai, India: Incidence and 28-Day Case Fatality. Neuroepidemology 2008;31:254-261. 
9. Salma N K, Ejaz A. Risk factors for stroke. A hospital based study. Pak J Med Sci 2007;23:17-22.

10. Mollah A S, Rahman SW, Das K K, Hassanuzzaman M. Characteristics of patients admitted with stroke. Mymensingh Med J 2007;16 (1):204.
11. Wade S, Joey D, Claibone J. Cerebrovascular Diseases. In: Fauci A, Braunwald E, Kasper DL, Hauser SL, Longo DL, editors. Harrison's Principle of Internal Medicine. 17th edition. NewYork; McGraw-Hill. 2008; 2: 2513-2536.

12. Pandit A, Arjyal A, Farrar J, Basnyat B. Neurological letter from. Oxford University Clinical Research Unit. Practical Neurology 2006;6:129-33. 